\title{
ELECTRIC DIPOLE MOMENTS AND RESONANCE IN MOLECULES.
}

\author{
By L. E. Sutron.
}

Received 28th February, I934.

\begin{abstract}
All electric dipole moment values herein quoted are given in Debye units, i.e., $\mathrm{x} \cdot \mathrm{ro}^{-18}$ e.s.u.
\end{abstract}

The idea that a molecule need not necessarily have a single Kossel Lewis-Langmuir electronic structure, but may be a hybrid of several such, is not new in chemistry. Recently, however, it has been given a much more definite meaning, and has been made amenable to quantititative treatment by the application of wave mechanics to the problem ; moreover, it is now realised how extensive the phenomenon is, owing largely to the work of Pauling and his collaborators on energies and internuclear distances. It is the purpose of this paper to show that it is possible, from electric dipole moment data, to decide independently whether or not there is resonance in a molecule, and also to obtain a rough idea of the nature of the more important parent structures and of their relative importance.

The conception under discussion arises because, if we attempt to treat a molecule by setting up a wave equation which is not the correct one, but differs from it only by a small perturbation term, then the actual wave functions of the molecule will be different linear combinations of all the solutions, or wave functions, of the approximate equation. The coefficients will denote the relative importance of these functions, in the actual one considered, and will depend upon the energies to which they correspond: thus, if we require the actual ground-state function, the coefficients of the higher excited states will be very small. If the approximate wave equation is such that the original functions correspond to single Kossel-Lewis-Langmuir structures, then the actual molecule will have to be pictured as a hybrid of these. The wave functions of equivalent structures, such as the two Kekule formulæ for benzene, will occur with equal coefficients.

The energy given by the actual wave function for the ground state will always be less than, or just equal to, that for any of the simple component structures, the difference being called the resonance energy, and consequently the actual state will be more stable than any of the parent states. Pauling and his collaborators have shown that in many molecules the actual heat of formation is less than that calculated for any simple structure, from the heats of rupture of simple links, and have attributed this to resonance. ${ }^{\mathbf{1}, \mathbf{2}}$

\section{Effect of Resonance on Steric Properties-Valency Angles.}

Resonance will affect other properties of a molecule, notably its steric characteristics. In benzene, for example, where each carboncarbon bond is a hybrid derived equally from a double bond, $\mathrm{C}=\mathrm{C}$, and a single one, $\mathrm{C}-\mathrm{C}$, they are all of equal length, I.42 $\AA$., which

1 Pauling and Sherman, J. Chem. Physics, 1, 606, 1933. 


\section{0}

\section{DIPOLE MOMENTS AND RESONANCE IN MOLECULES}

is nearer the length of a simple double bond, $\mathrm{I} \cdot 38 \AA$, than that of a simple single bond, $\mathrm{I} \cdot 54 \AA$. Pauling and his co-workers have, indeed, found as an empirical fact that in several molecules the length of a hybrid link is disproportionately near to that of the bond with the greater radial force constant. $\mathbf{3 , 4 , 5 , 6 , 7}$ Similarly, it is to be expected that, when a valency angle is altered by the electronic rearrangement necessary to change one parent structure to another, as in $\mathrm{A} / \mathrm{B}=\mathrm{C}$ changing to $\mathrm{A}-\mathrm{B} \equiv \mathrm{C}$, where it is changed from $125^{\circ}$ to $I 80^{\circ}$, it will actually take up a fixed intermediate value which will be disproportionately near to that in the stiffer structure, i.e. to $180^{\circ}$ in this example.

As is now well known, electric dipole moments can be used to obtain information about inter-covalency angles, and it is therefore to be expected that they can be used to detect resonance. It has, in fact, already been shown, from the non-polar nature of p-di-iso-cyanobenzene and of nickel carbonyl, that in the iso-cyanide group and the carbonyl radicle there must be considerable resonance of double bonded structures with triple bonded ones, with indication that the latter predominate, $8,9,10,11$

$$
\begin{aligned}
& -\mathrm{N}=\mathrm{C}-\mathrm{N} \rightrightarrows \mathrm{C} \\
& \text { Iso-cyanide group. }
\end{aligned}
$$

$$
\begin{aligned}
& -\mathrm{C}=\mathrm{O} \quad-\mathrm{C} \leftrightarrows \mathrm{O} \\
& \text { Carbonyl radicle. }
\end{aligned}
$$

The approximate additivity of the moment of the iso-thiocyanate group in para-substituted phenyl iso-thiocyanates with those of the substituent groups (phenyl iso-thiocyanate $\mu=3.00, p$-methyl phenyl isothiocyanate, $\mu=3.32$ obsd., 3.4 calc., $p$-chlorophenyl $i$ so-thiocyanate $\mu=\mathrm{I} \cdot 55$ obsd., I.44 calc., $p$-bromophenyl iso-thiocyanate $\mu=\mathrm{I} \cdot 54$ obsd., I.46 calc.) observed by Bergmann and Tschudnowsky, ${ }^{12}$ and the same property noticed by Sidgwick, Sutton and Thomas ${ }^{\mathbf{1 3}}$ for the isocyanate group (phenyl iso-cyanate $\mu=2 \cdot 23, p$-chlorophenyl iso-cyanate $\mu=0.82$ obsd., 0.67 calc.) indicate that in these groups there is resonance between the structures (I) and (II) below, for it is only (II) which requires a linear $\mathrm{R}-\mathrm{N}-\mathrm{C}-\mathrm{X}$ configuration:-

$$
\mathrm{R}-\mathrm{N}=\dot{\mathrm{C}}=\mathrm{X}
$$

$$
\mathrm{R}-\mathrm{N} \cong \mathrm{C} \rightarrow \mathrm{X}
$$

$$
\mathrm{R}-\mathrm{N} \leftarrow \mathrm{C} \leftrightarrows \mathrm{X}
$$

As will be shown later, if this is so then the structure (III) must also contribute and be approximately as important as (II).

In view of these conclusions, the moments of $I \cdot 89$ and $I \cdot 96$ found for carbodianil and its $p, p^{\prime}$-dimethyl derivative by Bergmann and Schütz ${ }^{14}$ indicate that similar resonance between the ordinary structure, $\mathrm{Ph}-\mathrm{N}=\mathrm{C}=\mathrm{N}-\mathrm{Ph}$, and $\mathrm{Ph}-\mathrm{N} \geqq \mathrm{C} \rightarrow \mathrm{N}-\mathrm{Ph}$ and $\mathrm{Ph}-\mathrm{N} \leftarrow \mathrm{C} \leftrightarrows \mathrm{N}-\mathrm{Ph}$ is ether non-existent or not very important, for it would tend to produce a linear molecule.

\footnotetext{
3 Pauling, Proc. Nat. Acad. Sciences, 18, 293, 1932.

Idem, 498.

5 Brockway, ibid., 19, 303, 1933.

Brockway and Pauling, ibid., 19, 860, 1933.

7 Brockway, ibid., 19, 868, 1933.

${ }^{8}$ Hammick, New, Sidgwick and Sutton, J. Chem. Soc., 1876, 1930.

New and Sutton, ibid., I4I5, r932.

10 Sutton and Bentley, Nature, 130, 314, 1932.

11 Sutton, New, and Bentley, $J$. Chem. Soc. $652,1933$.

12 Bergmann and Tschudnowsky, $Z$. physika. Chem., 17 B, Ior, I932.

${ }_{13}$ Sidgwick, Sutton, and Thomas, $J$. Chem. Soc., 406, 1933.

14 Bergmann and Schütz, Z. physikal. Chem., 19B, 389, I932.
} 
Resonance between structures $\mathrm{A}^{\mathrm{B}=\mathrm{C}}$ and $\mathrm{A}=\mathrm{B}=\mathrm{C}$, or $\mathrm{A}^{\prime}>_{\mathrm{C}}^{\mathrm{B}}$ and $\mathrm{A}=\mathrm{B}=\mathrm{C}$, could be detected in a similar manner but this has not yet been done in any actual case.

\section{Reduction of Freedom of Rotation.}

In some molecules resonance reduces the freedom of rotation of one part relative to another, because certain bonds which are single in the ordinary structure are double in some of the others and therefore acquire in part the properties of double bonds. Thus, since one parent structure of diphenyl is :-<smiles></smiles>

it would be expected that the two rings would be held coplanar with a rigidity depending upon the contribution of this, and similar structures, to the resonance energy (about 0.35 v.e. or $8 \mathrm{Kg}$. cals.) ${ }^{\mathbf{1}, 2} ; m, m^{\prime}$-Dichlorodiphenyl would have the same moment whether there were completely free rotation or there were only two possible configurations, cis and trans, and equal numbers of molecules occupied each ; in $0, o^{\prime}$-dichlorodiphenyl, however, there should be steric hindrance and dipole repulsion in the cis position so that possibly only the trans position would be occupied and the molecule would have no moment. This is not so, in actual fact, for the moments of this compound and of $o, o^{\prime}$ - dinitrodiphenyl are nearly those for free rotation, or equal occupation of cis and trans positions, being $I \cdot 72$ and $5 \cdot 12$ respectively while the calculated values ${ }^{15}$ are $I \cdot 9 I$ and $4 \cdot 8$. The mean energy in a vibrational degree of freedom at ordinary temperatures is $k T=0.6 \mathrm{Kg}$. cals. or 0.026 v.e., which is obviously far from sufficient by itself to overcome a resistance to rotation of the order given, but the whole of the resonance energy may not be lost when the planes of the rings are perpendicular, there may be steric repulsions between the substituent groups and the ortho hydrogen atoms, and the substituents may affect the resonance in the rings.

In benzalazine, $\mathrm{Ph}-\mathrm{CH}=\mathrm{N}-\mathrm{N}=\mathrm{CH}-\mathrm{Ph}$, freedom of rotation about the $\mathrm{N}-\mathrm{N}$ bond would similarly be reduced, but this again would be difficult to prove. Even if the carbon atoms were locked in the trans position there would still be three possible structures, (I), (II), (III), the first two being non-polar and the third slightly polar. The actua significance of the observed moment of $\mathrm{O} \cdot 89-\mathrm{I} \cdot \mathrm{O}$ is therefore uncertain<smiles>C(=N/N=C(c1ccccc1)c1ccccc1)\c1ccccc1</smiles>

${ }^{15}$ Williams, $Z$. physikal. Chem., 138, 75, 1928. 


\section{DIPOLE MOMENTS AND RESONANCE IN MOLECULES}

There is precisely the same difficulty in interpreting the moment of $\alpha, \delta$-dimethyl-butadiene, $0 \cdot 3 \mathrm{I}-0 \cdot 36,{ }^{\mathbf{1 6}}$ but the zero moment of $\beta, \gamma$ dimethyl-butadiene may indicate resonance. A determination of the moment of $\alpha, \alpha, \delta, \delta,{ }^{\prime}$-tetramethyl-butadiene would be more conclusive.

The independence of temperature shown by the moments of carboxylic esters, ${ }^{17,18,19}$ is usually considered to be due to the great attractive force between the $\mathrm{C}=\mathrm{O}$ and the $\mathrm{O}-\mathrm{R}$ link dipoles locking the group in the cis configuration, as suggested by Meyer, ${ }^{20}$ but Sturtevant has recently shown, by a more rigorous treatment, that the moment of single formic acid molecules should vary with temperature (from I.44 at $200^{\circ} \AA$. to 1.73 at $\left.500^{\circ} \AA.\right)^{21}$ and a similar variation would be expected in ester molecules if there were no forces except the inter-dipolar ones. The empirical fact of rigidity therefore indicates the existence of an additional force, which may well arise from resonance between the forms $-C_{\mathrm{O}}$ and $-C_{\mathrm{O}}^{\mathrm{O}}$; the inter-dipolar forces would then cause the cis position to be occupied in preference to the trans position. It is noteworthy that from thermochemical data the resonance energy in esters is found to be about $I \cdot 2$ v.e. per ester group, which is much larger than that between the rings in diphenyl, 0.35 v.e., or that in butadiene, 0.2 v.e. ${ }^{1}$

Further evidence of such stiffening in a molecule comes from the moments of some unsaturated ketones, which have been determined by Mr. Marsden and Mr. Bentley at Oxford, combined with some results of other workers. As will appear later, the observed values may be most consistently explained on the assumption that all the atoms of the conjugated system lie in a plane.

A special stereochemical effect of resonance is that which occurs in unsaturated rings which are stabilised by it. It requires the benzene molecule to have an axis of six-fold symmetry and a plane of symmetry perpendicular to this; this had already been shown to be so from the zero moment of benzene itself and of certain of its para-di- and I, 3, 5, tri-homosubstituted derivatives. ${ }^{22,23,24,25,36}$ Likewise naphthalene should be planar and is found to be so from similar evidence. ${ }^{26,27,28}$ The heterocyclic benzenoid ring compounds should also be planar, but this. has not yet been demonstrated from electric moment determinations.

\section{Electron Distribution.}

By far the greatest part of the evidence for resonance at present provided by electric dipole moment data comes, however, not from the in-

\footnotetext{
16 Farmer and Warren, J. Chem. Soc., I297, 1302, 1933.

17 Smyth and Dornte, $J$. Amer. Chem. Soc., 53, 2005, 1931.

18 Bretscher, Physikal. Z., 32, 765, I931.

${ }^{19}$ Zahn, Physic. Rev., 37, I516, I931 ; Physikal. Z., 33, 730, 1932.

${ }^{20}$ Meyer, $Z$. physikal. Chem, 8B, 27, r93o.

${ }^{21}$ Sturtevant, $J$. Amer. Chem. Soc., 55, 4478, 1933.

22 Sänger, Physikal. $Z$., 27, 165, 1926.

${ }^{23}$ Smyth and Morgan, $J$. Amer. Chem. Soc,, 49, 10зо, 1927.

24 Höjendahl, "Studies in Dipole Moment," Diss. Copenhagen, 1928.

25 Williams, Physikal. $Z$., 29, 174, 1928.

${ }^{26}$ Parts, $Z$. physikal. Chem., 10B, 264, 1930.

27 Williams and Fogelberg, J. Amer. Chem. Soc., 53, 2096, I93I.

28 Nakata, Ber., 64, 2059, I93I.
} 
formation which they give about spatial arrangement but from that which they give about electron distribution. It is permissible to regard the actual state of a resonating molecule as a statistical mean of those of the parent structures with the transitions between them occurring very rapidly, although they are, to a certain extent, only convenient mental pictures to enable us to visualise the attributes of the actual state; it is conceivable, therefore, that if we could perform an experiment in a time less than that between transitions $\tau$, we could detect the existence of separate structures. Since, however, $\tau=h \mid \Delta W$, where $h$ is Planck's constant and $\Delta W$ is the resonance energy, $\tau=4 \cdot 12$ (IO) ${ }^{-15}$ secs. if $\Delta W=$ I v.e., which is the usual order of magnitude, and it is obvious that such an experiment is practically impossible. If, then, we cannot detect any separate existence of two or more forms by an experiment which can be performed very rapidly, there is good reason for considering that resonance is occurring. The determination of electric dipole moments is such an experiment, for if a molecule exists in two or more forms which have lives longer than their times of relaxation in the electric field, the observed polarisation will be proportional to the arithmetic mean of the squares of the moments of the molecular species present (with weighting coefficients depending upon their relative concentrations); if the lives are shorter than the time of relaxation the polarisation will be proportional to the square of some mean of their moments. This time is of the order of $10^{-12}$ secs. in a gas and $10^{-7}$ secs. in the usual non-polar organic solvents, ${ }^{29}$ and if this is the maximum possible life, then clearly we have either extremely rapid tautomerism or electron resonance, probably the latter.

If a molecule may be represented by $\psi=\alpha_{1} \psi_{1}+\alpha_{2} \psi_{2}$, (where $\alpha_{1}^{2}+\alpha_{2}^{2}=1$ ), and if the moments of the parent states $\psi_{1}$ and $\psi_{2}$ along the $x$ axis are $\mu_{1 x}$ and $\mu_{2 x}$ respectively, then the moment of the hybrid state along this axis is

$\mu=e \int_{-\infty}^{+\infty} \psi^{*}\left(\sum_{i=1}^{n} x_{i}-a\right) \psi d \tau=\alpha_{1}{ }^{2} \mu_{1 x}+\alpha_{2}{ }^{2} \mu_{2 x}+2 \alpha_{1} \alpha_{2} e \int_{-\infty}^{+\infty} \psi_{1}^{*}\left(\sum_{i=1}^{n} x_{i}-a\right) \psi_{2} d \tau$,

where $e$ is the electronic charge, $a$ is the $x$ co-ordinate of the centroid of positive charge, and the suffix $i$ refers to the $i$ th electron, there being $n$ in all. Unfortunately, the integral cannot be given a general evaluation, so that there is no simple, exact, general relation between $\mu_{x}$ and $\alpha_{1}, \alpha_{2}, \mu_{1 x}$ and $\mu_{2 x}$ : but, although it cannot be neglected altogether, it is probably considerably less than the sum of the first two terms, in most cases, so we may form a rough idea of the ratio of the coefficients if we know the three moments.

In the case of a molecule such as carbon dioxide it would be expected that equivalent structures of equal and opposite polarity, $\mathrm{O} \rightrightarrows \mathrm{C} \rightarrow \mathrm{O}$ and $\mathrm{O} \leftarrow \mathrm{C} \leqq \mathrm{O}$, would have equal coefficients, ${ }^{*}$ and that the cross term would vanish making $\mu=0$, which is, indeed, actually so. Resonance of this important type therefore cannot be detected from the magnitude of the moment alone. For an unsymmetrical molecule, say $A-B$, derived from $\stackrel{+}{\mathrm{A}}-\overline{\mathrm{B}}$ and $\overline{\mathrm{A}}-\stackrel{+}{\mathrm{B}}$, wherein by chance $\alpha_{1}{ }^{2} \mu_{1}=-\alpha_{2}{ }^{2} \mu_{2}$, the cross term need not necessarily vanish and the molecule might be polar.

29 Ebert, Leipziger Vorträge, Leipzig, p. 55, 1929.

* This is required by the nuclear symmetry found from spectroscopic data. 


\section{DIPOLE MOMENTS AND RESONANCE IN MOLECULES}

If the actual moment of a compound is zero, or is very small, although simple structures for it would all be polar, then it is almost certain that there is resonance between structures of opposite polarity: thus, carbon monoxide, nitric oxide, and nitrous oxide have moments of $0 \cdot 12$, $0 \cdot I$, and $0 \cdot 0$ respectively, while the possible simple structures and their moments are :-

$$
\text { CO } \mathrm{C}=\mathrm{O}-2.7 ; \mathrm{C} \leftrightarrows \mathrm{O} 5.5-4 . \mathrm{I}=\mathrm{I} \cdot 4\left(\text { see }^{8}\right)
$$

this value, which is calculated on the assumption that the degree of asymmetry of sharing in the triple bond is the same as that in the double bond, is an upper limit);

$$
\text { NO }: \dot{\mathrm{N}} \vdots \ddot{\mathrm{O}}:-\mathrm{I} \cdot 65^{30} ;: \ddot{\mathrm{N}} \vdots \dot{\mathrm{O}}: 5 \cdot 45-\mathrm{I} \cdot 65=3 \cdot 8
$$

(the difference is due to the transference of an electron from the oxygen nucleus to the nitrogen, a distance of $I^{\circ} I_{5} \AA$., which is assumed not to alter the asymmetry of sharing. This value, also, is an upper limit) ; ${ }^{\mathbf{3 1}}$

$$
\mathbf{N}_{2} \mathbf{O} \quad \mathrm{N} \leftarrow \mathrm{N}=\mathrm{O} \quad 5.3-\mathbf{I} \cdot 65=3.65
$$

(assuming symmetric sharing between the nitrogen atoms, and an $\mathrm{N}-\mathrm{N}$ distance of $\mathrm{I} \cdot \mathrm{IO} \AA$.) ;

$$
\mathrm{N} \equiv \mathrm{N} \rightarrow \mathrm{O}-5 \cdot 8-0.8=-6.6
$$

(assuming the degree of asymmetry of sharing to be the same in the single $\mathrm{N}-\mathrm{O}$ link as in the double one) ${ }^{32,3,33}$

Approximate as these values are, they suffice to show that in carbon monoxide the triple bonded structure predominates, and to indicate that in nitric oxide the two structures are of about equal importance while in nitrous oxide the double bonded one is the more important.

Electric moment data alone cannot give a complete answer to the question of the structure of the organic azides and the aliphatic diazocompounds, but they show quite definitely that these have either ring structures or hybrid chain structures derived roughly equally from $\mathrm{R}-\mathrm{N}=\mathrm{N} \rightarrow \mathrm{N}$ and $\mathrm{R}-\mathrm{N} \leftarrow \mathrm{N} \equiv \mathrm{N}, \mathrm{R}_{2}=\mathrm{C}=\mathrm{N} \rightrightarrows \mathrm{N}$ and $\mathrm{R}_{2}=\mathrm{C} \leftarrow \mathrm{N} \equiv \mathrm{N}$ respectively, because the actual moments are small, $\mathrm{I} \cdot 55$ and $\mathrm{I} \cdot 42$, whereas those for all these parent structures would be at least $\pm 3 \cdot{ }^{\mathbf{1 3}}$ The ring structure for the azides has now been eliminated by measurements of interatomic distances ${ }^{6}$ which have also confirmed the conclusion that the alternative structure must be a hybrid one, so the structure of both types of compound is now settled beyond reasonable doubt.

For similar reasons, if, as other evidence indicates (p. 790), there is resonance in the $i s o$-cyanates and iso-thiocyanates between structures $\mathrm{Ph}-\mathrm{N}=\mathrm{C}=\mathrm{X}$ and $\mathrm{Ph}-\mathrm{N} \leftrightarrows \mathrm{C} \rightarrow \mathrm{X}$ there must also be resonance with a third one, $\mathrm{Ph}-\mathrm{N} \rightrightarrows \mathrm{C} \rightarrow \mathrm{X}$, and these latter two must contribute equally, for they would both have very large moments because of their parallel coordinate links, (ca. 6-9), whereas the actual moments are approximately those which would be calculated for the ordinary structures alone (assuming $\mu_{\mathrm{PhN}}=-\mathrm{I} \cdot 34, \quad \mu_{\mathrm{N}=\mathrm{C}}=-\frac{2}{3} \cdot \mu_{\mathrm{C} \equiv \mathrm{N}}=+2 \cdot 4, \quad$ and $\mu_{\mathrm{C}=0}=-2 \cdot 75$, then $\mu_{\mathrm{PhNCO}}=-\mathrm{I} \cdot 7$, obsd., $-2 \cdot 23$; assuming $\mu_{\mathrm{C}=\mathrm{S}}=3.4{ }^{34}$ then $\mu_{\text {PHNCS }}=2 \cdot 34$, obsd., $3 \cdot 00$ ). Again, the structure $\mathrm{Ph}-\mathrm{N}=\mathrm{S} \rightarrow \mathrm{O}$ for thionyl aniline would require a moment of about -6 , whereas the actual

\footnotetext{
${ }^{30}$ Hammick, New and Sutton, J. Chem. Soc., 746, 1932.

31 Pauling, J. Amer. Chem. Soc., 53, 3231, r931.

32 Plyler and Barker, Physic. Rev., 38, 1827, 1931.

3s Pauling, Proc. Nat. Acad. Sciences, 18, 498, I932.

s4 Hunter and Partington, $J$. Chem. Soc., 87, I933.
} 
value observed is $3.00 ;{ }^{12}$ there must. therefore, be resonance between the above structure and the one $\mathrm{Ph}-\mathrm{N} \leftarrow \mathrm{S}=\mathrm{O}$. In the case of the isocyanides, on the other hand, the observed moment, -3.45 , is almost exactly equal to the value -3.34 calculated for the triple bonded structure $\mathrm{R}-\mathrm{N} \cong \mathrm{C}$ (taking the $\mathrm{N} \equiv \mathrm{C}$ distance as $\mathrm{I}^{\circ} \mathrm{I}_{5} \AA .{ }^{9}$ ) thus showing that this form predominates.

p-Dinitrobenzene, I, 3, 5, -trinitrobenzene and similar compounds should be non-polar if the nitro-group is a hybrid of $-\mathrm{N}_{{ }_{O}}$ and $-\mathrm{N}_{\mathrm{O}}^{7 \mathrm{O}}$ but, although this is probably the case, it is not proved beyond doubt by existing data; the measurements of the temperature variation of the polarisation by Parts and by Lütgert were made only over a range of $30^{\circ}-40^{\circ} .25,35,36,37$

The moment of acetyl chloride, $2 \cdot 68$, indicates some resonance of the ordinary structure $-\mathrm{C}_{\mathrm{O}}^{\mathrm{Cl}}$ with the one $-\mathrm{C}_{\mathrm{O}}^{\mathrm{Cl}}$, since the moment calculated for the first one is $2 \cdot 3$ (from the moments of acetone, $2 \cdot 75$, and tert-butyl chloride, $2 \cdot 15$, and assuming an angle of $\left.125^{\circ}\right)$ : polarisation by distortion of the $\mathrm{C}-\mathrm{Cl}$ moment by the $\mathrm{C}=\mathrm{O}$ moment, or the converse process, would not explain the increase of moment. The moments of esters and of substituted amides cannot yet be interpreted with certainty, because of the uncertainty regarding the oxygen and the nitrogen valency angles and the degree of free rotation in the amides.

\section{Resonance in Conjugated Compounds.}

An important type of resonance is that which occurs in unsaturated carbon compounds which have conjugate groups attached. If the group is such that an atom with unshared electrons is attached by a single bond to one of the unsaturated carbon atoms, there can be resonance between the ordinary form $-\mathrm{C}=\mathrm{C}-\ddot{\mathrm{X}}-\mathrm{Y}$ and an excited one n

$-\ddot{\mathrm{C}}-\mathrm{C}=\mathrm{X}-\mathrm{Y}$, setting up a dipole moment with the positive pole towards the group: if the carbon system is further conjugated, there may be other contributing structures such as $\stackrel{\cap}{\mathrm{C}}-\mathrm{C}=\mathrm{C}-\mathrm{C}=\mathrm{X}-\mathrm{Y}$. If, on the other hand, the group is such that the atom next the carbon system is attached to another one by a multiple bond, then there can be resonance between the ordinary structure, say $-\mathrm{C}=\mathrm{C}-\mathrm{X}=\mathrm{Y}$, and excited ones of the type $-\mathrm{C}-\mathrm{C}=\mathrm{X}-\ddot{\mathrm{Y}}$, setting up a moment with the negative pole towards the group. Other structures such as $-\mathrm{C}-\mathrm{C}=\mathrm{X}-\mathrm{Y}$ may also contribute, indeed, if $\mathrm{X}$ and $\mathrm{Y}$ are carbon atoms, these are much more important than those involving asymmetric displacements; ${ }^{\mathbf{2}, 38}$ they would be expected to cause small changes of moment in the direction opposite to the moment of the normal $\mathrm{X}-\mathrm{Y}$ link. Such structures, with nearly symmetric displacements, cannot occur with the first type of group unless the atom $\mathrm{X}$ can have more than four strong wave

\footnotetext{
35 Parts, $Z$. physikal. Chem., 4B, 227, 1929.

36 Tiganik, ibid., I3B, 425, I93I.

37 Litgert, ibid., 14B, 3I, I $93 \mathbf{I}$.

${ }^{38}$ Pauling and Wheland, $J$. Chem. Physics, 1, 362, I933.
} 
functions in its outer group. When groups of these types are attached to benzene there will be contributions from all the possible structures of the above kinds, in addition to those which contribute to the normal benzene molecule, and the coefficients will depend upon how close their energies are to those of the latter class of structure. It should be mentioned that the results obtained by Hückel from an earlier treatment ${ }^{39}$ would necessitate the changes of moment being in the opposite directions to the above. It will immediately be recognised that the foregoing is largely a translation into different terminology of some of the postulates of the theories of organic reaction developed by Robinson, ${ }^{\mathbf{4 0}}$ and by Ingold ; ${ }^{41,42}$ one difference, however, is that it is now evident that structures with three electron bonds cannot be important, for in these it would be necessary either that some, of the carbon atoms use five outer wave functions, or else that the three electron bonds be of the weak type suggested to exist in certain molecules by Pauling, ${ }^{31}$ and in either case the energy content would be very different from those of the ordinary state or of the low excited states described above.

The method of detecting such resonance has already been described and applied: ${ }^{\mathbf{4 3}}$ it is to determine the vector difference between the moments of a standard aliphatic and a standard unsaturated or aromatic state, the tert-butyl and the vinyl or phenyl compounds being chosen, since these hydrocarbon radicles have nearly the same polarisability.* This vector, called $\mu_{e}$, will have a positive component along the axis $R-X$ if the group is of the first type, and a negative one if it is of the second

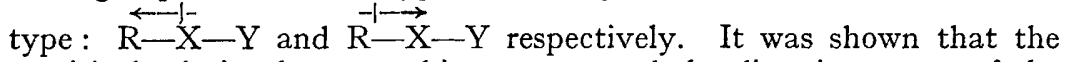
empirical relation between this moment and the directive power of the substituent group was that required by the Robinson-Ingold theory, and therefore by the general principles given above, but not by the Hückel theory. Subsequent data have, in general, supported this conclusion; the nitroso-group, which might be of either type, was found actually to be of the second..$^{\mathbf{3 0}, \mathbf{1 1}}$ Some typical results are given below; $\phi_{1}$ and $\phi_{2}$ are the angles between the link $R-X$ and the resultant moments of the aliphatic and aromatic compounds respectively :-

TABLE I.

\begin{tabular}{|c|c|c|c|c|c|c|c|}
\hline & & $\mu$ & & & $\mu$ & & \\
\hline Group. & Vingl & Pbenyl & -Naphthyl. & $\phi_{2}$ & Aliph. & $\phi_{1}$. & $\mu_{e}$. \\
\hline $\begin{array}{l}-\mathrm{Cl} \\
-\mathrm{OCH} \\
-\mathrm{NH}_{2} \\
-\mathrm{NO}_{2} \\
-\mathrm{CHO} \\
-\mathrm{NO}\end{array}$ & $\begin{array}{c}x \cdot 66 \\
- \\
- \\
-\end{array}$ & $\begin{array}{l}\mathbf{I} \cdot 56 \\
I \cdot 19 \\
I \cdot 55 \\
3.93 \\
2 \cdot 75 \\
3 \cdot 14\end{array}$ & $\begin{array}{l}I \cdot 59 \\
- \\
3 \cdot 62 \\
-\end{array}$ & $\begin{array}{l}180^{\circ} \\
75 \\
45 \\
\mathrm{x} 80 \\
\mathrm{I} 42 \cdot 5 \\
\mathrm{I} 58\end{array}$ & $\begin{array}{l}2 \cdot 15 \\
I \cdot 29 \\
I \cdot 23 \\
3 \cdot 29 \\
2 \cdot 46 \\
2 \cdot 51\end{array}$ & $\begin{array}{r}\text { I } 80^{\circ} \\
\left(\begin{array}{l}1 \\
1\end{array}\right) \\
80 \\
\text { I } 80 \\
125 \\
148\end{array}$ & $\begin{array}{r}+0.49 ;+0.59 ;+0.56 \\
-\quad ;+0.75 ;-0.89 ;- \\
-\quad ;-0.64 ;-0.33 \\
-\quad ;-1.05 ;-0.8 ;-\end{array}$ \\
\hline
\end{tabular}

${ }^{3}$ Hückel, $Z$. Physik, 72, 310, 1931.

40 Robinson, Rapp. Inst. Intern. Chim. Solvay, p. 423, I931.

41 Ingold, Rec. Trav. Chim., 48, 797, 1929.

42 Ingold, $J$. Chem. Soc., 1120, r933.

43 Sutton, Proc. Roy. Soc., 133A, 668, x93I.

* The choice of an aliphatic standard is necessarily somewhat arbitrary, but the tert-butyl or sec-propyl compounds actually give results which agree with the chemical evidence. The enhanced reactivity of the compounds is not necessarily an objection to their use for this purpose, the point being that the benzene compounds might be similar if resonance with the group did not occur. 
We may assess the relative importance of excited and ordinary structures in several compounds by calculating the changes of moment $\mu_{\mathrm{E}}$ which occur in the formation of the former structures from the latter, these changes being roughly the same for groups of the same type, and comparing these with the observed values of $\mu_{e} \dagger$ In the above cases, $\mu_{\mathrm{e}}$ is from $0 \cdot 2$ to $\mathrm{I} \cdot \mathrm{O}$ while $\mu_{\mathrm{E}}$, parallel to the $\mathrm{R}-\mathrm{X}$ bond, is from $3 \mathrm{el} / 2$ to $3 \mathrm{el}$, i.e. from Io to $20, \ddagger$ and therefore the excited structures are much less important than the ordinary ones. The fact that the moments of the halogen compounds are reduced by these effects proves that there is resonance, for if transitions were more than $10^{-7}$ secs. apart the moments would be increased (see p. 793) since all excited structures would have moments numerically greater than that of the ordinary structure.

The moments of some conjugated ketones and aldehydes, to which reference has already been made, are interesting because they show that the extra moments arise in the links themselves, independently of their relative orientation in space, and thus that they are not due to polarisation through space by the carbonyl group. The moments of 3, 5cyclo-hexanone and of pulegone are 3.79 and 2.95 respectively: if we assume that the moment in each $\mathrm{C}=\mathrm{C}$ group is $0.5+x, 0.5$ representing the effect of the saturated carbon atoms (the moment of $\alpha$, $\alpha^{\prime}$-di-methyl-butadiene is $0.52^{16}$ ) and $x$ the effect of conjugation with the $\mathrm{C}=\mathrm{O}$ group, and that the moment of the $\mathrm{C}=\mathrm{O}$ link is $y$, then we find that $x=0.18$ and $y=3.1 \mathrm{I}$, the latter value being 0.36 larger than it is in acetone $(2 \cdot 75)$. If we assume further that in $\alpha$ mono-benzalcyclo-hexanone the benzene ring is turned away from the $\mathrm{C}=\mathrm{O}$ link, as shown, then we find that the moment $z$ in the ring is O.I. From these three parameters, and on the suppositions that there is no freedom of rotation and that the configurations are those in which steric interference is a minimum, the moments of other similar compounds have been calculated; some of the results are given in Table II.<smiles>CC1CC(=O)C(C)C(C)(C)C1</smiles>

3, 5, -Dimethyl-cyclohexenone.<smiles>CC(C)=C1CCC(C)CC1=O</smiles>

Pulegone.<smiles>CC(=O)C1=CCCCC1</smiles>

$\alpha$-Benzal-cyclo-hexanone.

† If $\mu=\alpha_{1}{ }^{2} \mu_{1}+\alpha_{2}{ }^{2} \mu_{2}+\alpha_{3}{ }^{2} \mu_{3}+\ldots$., neglecting cross terms, where $\alpha_{1}{ }^{2}+$ $\alpha_{2}^{2}+\alpha_{3}^{2}+\cdots=I, \mu=\mu_{1}+\alpha_{2}{ }^{2}\left(\mu_{2}-\mu_{1}\right)+\alpha_{3}{ }^{2}\left(\mu_{3}-\mu_{1}\right)+\ldots .$. and if $\mu_{2}-\mu_{1}=\left(\mu_{3}-\mu_{1}\right) / n$ etc. then $\left(\mu-\mu_{1}\right) /\left(\mu_{2}-\mu_{1}\right)=\alpha_{2}{ }^{2}+n \alpha_{3}{ }^{2}+p \alpha_{4}{ }^{2}+\ldots$. $=\mu_{c} / \mu \mathrm{s}$

$\ddagger$ No allowance has been made, in calculating these values, for the distortion polarisation produced by the transference moments. Since, in a physical dipole, such distortion of the medium between the poles reduces the total moment whereas that outside the poles increases it, it is probable that the effect would be to decrease the larger value, $3 \mathrm{el}$, where the poles are at opposite ends of the molecule, and to increase the smaller one, $3 \mathrm{el} / 2$, where, in the larger molecules, a considerable part of the molecule is outside of the poles. Thus the values given are probably upper and lower limits. 
TABLE II.

\begin{tabular}{|c|c|c|}
\hline Compound. & ${ }^{\mu}$ Calc. & $\mu_{\text {Obsd. }}$ \\
\hline 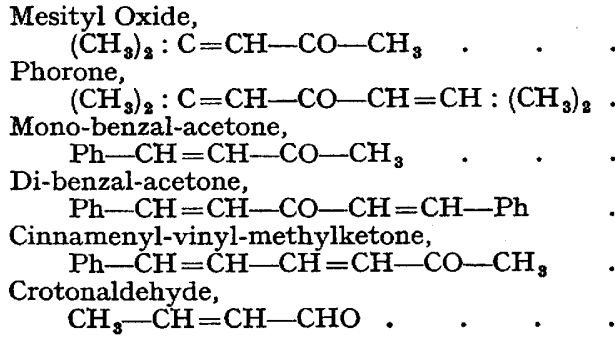 & $\begin{array}{l}2.95 \text { min. } \\
2.64 \quad " \\
3.32 \max . \\
3.5 \quad " \\
3.5 \quad " \\
3.64 \quad "\end{array}$ & $\begin{array}{l}2 \cdot 80 \\
2 \cdot 38 \\
3 \cdot 31 \\
3 \cdot 28 \\
3 \cdot 45 \\
3 \cdot 54\end{array}$ \\
\hline
\end{tabular}

It will be noticed that the observed values for mesityl oxide and phorone are even less than the minimum values calculated, which indicates that the valencies attaching the radicles to the $\mathrm{C}=\mathrm{O}$ group may be at more than $110^{\circ}$ to one another (an angle of $120^{\circ}$ gives $\mu_{\text {Phorone }}=2.5$ ). That the changes of moment are not due mainly to distortion polarisation through the bonds (cf. 43) is shown by the constancy of the moments of the saturated ketones, substitution of methyl groups by tert-butyl groups causing no change. ${ }^{\mathbf{4 4}}$

Both phenyl-ethylene and phenyl-acetylene are reported to have small moments, 0.56 and $0.66-0.83$ respectively, indicating some contribution from asymmetric structures: the moments of $p$-nitro-phenylacetylene and nitrobenzene, 3.63 and 3.93 , show that the phenyl-acetylene moment is negative relative to the ring. $45,46,47$

The moments of toluene, the $\omega$-substituted toluenes, and the sulphones are of interest, inasmuch as they indicate that structures with asymmetric displacements may contribute, even when the groups cannot conjugate with the ring:-

TABLE III.

\begin{tabular}{|c|c|c|c|c|c|c|c|}
\hline Group. & Vinyl & ${ }^{\mu}$ Phenyl. & $\phi_{2}$ & $\begin{array}{c}\mu \\
\text { Aliph. }\end{array}$ & $\phi_{1}$. & & $\mu_{e} \cdot$ \\
\hline $\begin{array}{l}-\mathrm{CH}_{3} . \\
-\mathrm{CCl}_{3} . \\
-\mathrm{CH}_{2} \mathrm{NO}_{2} \\
>\mathrm{SO}_{2}\end{array}$ & $\begin{array}{l}0.35 ; \\
-; \\
-;\end{array}$ & $\begin{array}{l}; \quad 0.4 \\
; \quad 2.07 \\
3.30 \\
5.1\end{array}$ & $\begin{array}{r}0^{\circ} \\
180 \\
119 \\
55\end{array}$ & $\begin{array}{l}0 \\
1 \cdot 57 \\
3 \cdot 29 \\
4 \cdot 4\end{array}$ & $\begin{array}{c}0^{\circ} \\
180 \\
\left(\begin{array}{l}1 \\
10\end{array}\right) \\
55\end{array}$ & $\begin{array}{r}+0.35 \\
-\quad \vdots \\
-\quad \vdots\end{array}$ & $\begin{array}{l}+0.4 \\
-0.5 \\
-0.6-1 \cdot 0.48 \\
-0.7\end{array}$ \\
\hline
\end{tabular}

It is entirely possible that the strong electric fields in the neighbourhood of polar groups would act as perturbations large enough to make asymmetric ring structures much more important than they are in benzene itself. ${ }^{49,11}$ Such effects should also occur when the groups can con-

14 Wolf, $Z$. physikal. Chem., 2B, 39, 1929.

${ }^{45}$ Gallay, Kolloid $Z$., 57, I, I93I.

${ }^{46}$ Smyth and Dornte, J. Amer. Chem. Soc., 53, I296, I93I.

47 Bergmann and Engel, $Z$. physikal. Chem., I7B, I 16, 1932.

${ }^{48}$ Unpublished measurements and calculations by Mr. F. C. Frank.

49 Baldwin and Robinson, J. Chem. Soc., I445, 1932. 
jugate and may then either accentuate or diminish the asymmetry, according to the nature of the group. ${ }^{\mathbf{4 0}, \mathbf{4 1}, \mathbf{4 2}}$

When two groups of opposite type are substituted into the same benzene ring each reinforces the type of resonance characteristic of the other, and these secondary effects sometimes cause the compound to have an abnormal moment. For many pairs of groups it is $\ngtr 0.15$ but for some it is $\mathrm{I} \cdot \mathrm{o}$ (e.g. $p$-nitroaniline) and in $p$-nitroso-dimethylaniline and some similar compounds it is $>2:{ }^{50,51}$ even in such compounds as these, it appears that the ordinary structures are still the more important ones. It is possible that the abnormalities of ortho-disubstituted benzenes may also be due in part to such effects.

\section{Heterocyclic Compounds.}

Unsaturated heterocyclic compounds show similar evidence of resonance. Furane, thiophene, and pyrrole can have parent structures of the types 1,42 of which the second and third are equivalent as are also the fourth and fifth:-<smiles>[V]=C1C=CC=C1</smiles>

Ordinary.<smiles>c1ccccc1</smiles>

X<smiles>Cc1ccccc1C</smiles>

Excited.<smiles>[X]c1ccccc1-c1ccccc1</smiles>

Pyridine and its homologues can be composed of the ordinary benzene-like structures, of the Kekule and Dewar types, and the following excited ones, which are divided into two groups corresponding to the direction of $\mu_{E}$; the number of equivalent structures of each kind is shown by a bracketed figure:-<smiles>CC1C(C)C2(C)NC1(C)NC2(C)C</smiles>

(2)<smiles>CC1C(C)C2(C)C(C)NC1(C)C2C</smiles>

(2)<smiles>C[C]1C(C)=C(C)N=C(C)C1C</smiles>

(I)

$\uparrow \mu_{\mathbf{H}}$<smiles>Cc1[nH]c(C)c(C)c1C</smiles>

(2)<smiles></smiles>

(I)

Group I.

so Hampson and Sutton, Proc. Roy. Soc., 140A, 572, 1933.

${ }^{51}$ Idem, I43A, ${ }_{47}, 1933$. 
<smiles>CC1C(C)C2(C)CN1C(C)C2(C)C</smiles>

(2)<smiles>CC1=NC(C)C(C)=C(C)C1C</smiles>

(2)<smiles>Cc1nc2c(C)c(C)c1CC2C</smiles>

(2)

$\downarrow \mu_{\mathrm{E}}$<smiles></smiles>

(2)<smiles>Cc1nc(C)c(C)c(C)c1C</smiles>

(I)

Group 2.

All the excited structures for furane and thiophene, and those of the first group for pyridine, have moments in the opposite direction to those of the ordinary structures, and are greater; in pyrrole, the moment of the $\mathrm{N}-\mathrm{H}$ link may reverse the moment of the ordinary form, so the opposite may be true; the excited pyridine structures of the second group have moments in the same direction as, and greater than those of the ordinary forms. Thus, if the ordinary structures are more important than the excited ones shown, the moments of furane and thiophene will be decreased, while those of pyrrole and $N$-methyl pyrrole will be increased; those of pyridine and its homologues may be either decreased or increased. The moments do, in fact, change in this manner but whether or not the above interpretation is correct cannot be decided until the directions of the resultant moments relative to the molecule have been determined. The available data are the following:-

TABLE IV.

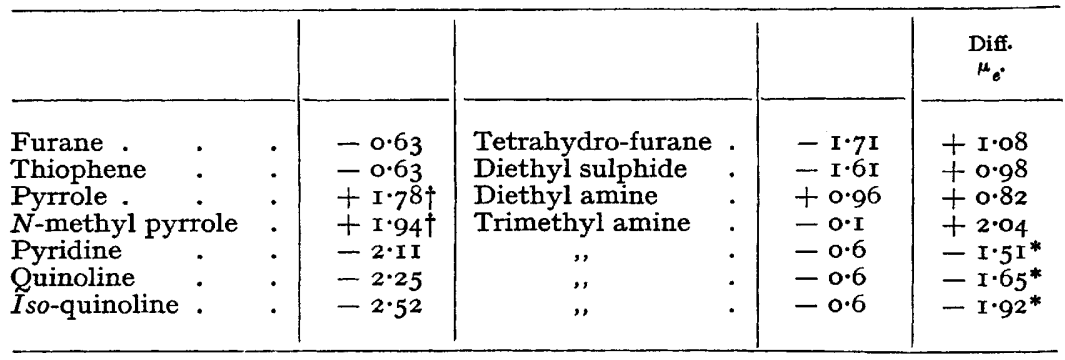

The signs ascribed are those which seem the most probable at present : the moment given for the aliphatic analogue of $N$. methyl pyrrole is

* No allowance has been made for differences in inter-valency angles.

† Unpublished results of J. Jackson, $c f$. Cowley and Partington, J.C.S., I259, r933. 
that of two $\mathrm{C}-\mathrm{N}$ bonds at $109.5^{\circ}$ to each other and a third at $125.25^{\circ}$ to each, and is taken as $-0.15 \times 0.6=-0.1$. For the five-membered rings $\mu_{\mathrm{E}}$ is from 0.588 el to $\mathrm{I} .539 \mathrm{el}$, i.e. from 4 to $\mathrm{IO}$, while for pyridine it is $\mathrm{el} / 2$ to $2 \mathrm{el}$, i.e. from 3.5 to I4, and since $\mu_{B}$ is I to $\mathrm{I} \cdot 5$, it appears that the asymmetric excited states are relatively more important than they are in the substituted benzenes.

Heterocyclic compounds containing groups of opposite types show secondary ffects, the $\boldsymbol{\gamma}$-pyrones and $\boldsymbol{\gamma}$-thiopyrones being good examples. ${ }^{34}$ The moments calculated from the values for divinyl ether, $\mathrm{I} \cdot 06$, benzophenone, 3.04 , thio-benzophenone 3.37 , and propylene 0.35 , for dimethyl- $\gamma$-pyrone, diphenyl- $\gamma$-pyrone, and dimethyl- $\gamma$-thiopyrone are $2 \cdot 68$, I.98 and 3.01 , whereas the observed values are $4.05,3.82$ and 5.05 respectively, the differences being $\mathrm{I} \cdot 37, \mathrm{I} \cdot 84$ and $2 \cdot 04$. The moment corresponding to the change from a completely aliphatic system to the actual one in dimethyl- $\gamma$-pyrone (calculated from the moments of diethyl ether, $I \cdot 29$, and acetone, $2 \cdot 75)$ is $4 \cdot 05-(2 \cdot 75-I \cdot 3)=2 \cdot 6$, but since the moment $\mu_{\mathrm{E}}$, for the excited structure shown (from which the cation is derived) is approximately 3 el., i.e. 20 , the ordinary structure is still the more important, and this must also be true in the $\gamma$-thiopyrones.<smiles></smiles>

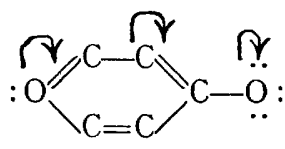

Excited.

The conclusions in this paper confirm and extend those reached by Pauling and other workers from quite different evidence, and therefore serve to emphasise the reality of the phenomenon of resonance in molecules.

The author would like to thank Professor L. Pauling and Dr. E. B. Wilson for many discussions and suggestions from which this paper has greatly benefited.

The Gates Chemical Laboratory, California Institute of Technology, Pasadena. 